\title{
Long-Term Treatment and Diagnosis of Tetrahydrobiopterin-Responsive Hyperphenylalaninemia with a Mutant Phenylalanine Hydroxylase Gene
}

\author{
HARUO SHINTAKU, SHIGEO KURE, TOSHIHIRO OHURA, YOSHIYUKI OKANO, \\ MISAO OHWADA, NARUJI SUGIYAMA, NOBUO SAKURA, ICHIRO YOSHIDA, \\ MAKOTO YOSHINO, YOICHI MATSUBARA, KEN SUZUKI, KIKUMARO AOKI, AND \\ TERUO KITAGAWA \\ Department of Pediatrics, Osaka City University Graduate School of Medicine, Osaka 545-8585, Japan \\ [H.S., Y.O.], Department of Medical Genetics [S.K., Y.M.], Department of Pediatrics [T.O.], Tohoku \\ University School of Medicine, Sendai 980-8574, Japan, Department of Pediatrics, Nihon University \\ Hospital, Tokyo 173-8610, Japan [M.O.], Division of Pediatrics, Yokkaichi Municipal Hospital, Yokkaichi \\ 510-8567, Japan [N.Su.], Department of Pharmacodynamics, Hiroshima University Graduate School of \\ Medicine, Dentistry and Pharmacy, Hiroshima 734-8551, Japan [N.Sa.], Department of Pediatrics, \\ Kurume University School of Medicine, Kurume 830-0011, Japan [I.Y., M.Y.], Tokyo Health Service \\ Association, Tokyo 162-8402, Japan [K.S., T.K.], Department of Health and Nutrition, Kagawa Nutrition \\ University, Sakado 350-0288, Japan [K.A.]
}

\begin{abstract}
A novel therapeutic strategy for phenylketonuria (PKU) has been initiated in Japan. A total of 12 patients who met the criteria for tetrahydrobiopterin $\left(\mathrm{BH}_{4}\right)$-responsive hyperphenylalaninemia (HPA) with a mutant phenylalanine hydroxylase (PAH) (EC 1.14.16.1) gene were recruited at 12 medical centers in Japan between June 1995 and July 2001. Therapeutic efficacy of $\mathrm{BH}_{4}$ was evaluated in single-dose, four-dose, and 1-wk $\mathrm{BH}_{4}$ loading tests followed by long-term $\mathrm{BH}_{4}$ treatment, and also examined in relation to the PAH gene mutations. The endpoints were determined as the percentage decline in serum phenylalanine from initial values after single-dose $(>20 \%)$, four-dose $(>30 \%)$, and 1-wk $\mathrm{BH}_{4}(>50 \%)$ loading tests. Patients with mild PKU exhibiting decreases in blood phenylalanine concentrations of $>20 \%$ in the single-dose test also demonstrated decreases of $>30 \%$ in the four-dose test. The 1 -wk test elicited $\mathrm{BH}_{4}$ responsiveness even in patients with poor responses in the shorter tests. Patients with mild HPA, many of whom carry the R241C allele, re-
\end{abstract}

\section{ABSTRACT}

sponded to $\mathrm{BH}_{4}$ administration. No clear correlation was noted between the degree of decrease in serum phenylalanine concentrations in the single- or four-dose tests and specific PAH mutations. The 1 -wk test $\left(20 \mathrm{mg} / \mathrm{kg}\right.$ of $\mathrm{BH}_{4}$ per day $)$ is the most sensitive test for the diagnosis of $\mathrm{BH}_{4}$-responsive $\mathrm{PAH}$ deficiency. Responsiveness apparently depends on mutations in the $\mathrm{PAH}$ gene causing mild $\mathrm{PKU}$, such as $\mathrm{R} 241 \mathrm{C}$. $\mathrm{BH}_{4}$ proved to be an effective therapy that may be able to replace or liberalize the phenylalanine-restricted diets for a considerable number of patients with mild PKU. (Pediatr Res 55: 425-430, 2004)
PKU, phenylketonuria
$\mathbf{B H}_{4}$, tetrahydrobiopterin
PHA, hyperphenylalaninemia
PAH, phenylalanine hydroxylase

Abbreviations
HPA results from the deficiency of PAH enzyme activity or its cofactor, $\mathrm{BH}_{4}$. In 1999, Kure et al. (1) reported four patients with $\mathrm{PAH}$ deficiency who showed a decrease in blood phenylalanine elevations after $\mathrm{BH}_{4}$ loading. $\mathrm{BH}_{4}$ is known to normalize blood phenylalanine in $\mathrm{BH}_{4}$ deficiency, but not in PKU.

Received February 19, 2003; accepted August 18, 2003.

Correspondence: Haruo Shintaku, M.D., Department of Pediatrics, Osaka City University Graduate School of Medicine,1-4-3, Asahimachi, abeno-ku, Osaka 545-8585, Japan; e-mail: shintakuh@med.osaka-cu.ac.jp

DOI: 10.1203/01.PDR.0000111283.91564.7E
However, Shintaku et al. (2) found that 5 patients of 15 with mild HPA (serum phenylalanine $<20 \mathrm{mg} / \mathrm{dL}$ ) showed a gradual decrease of serum phenylalanine at $24 \mathrm{~h}$ with $\mathrm{BH}_{4}$ loading, although no patient with classical PKU (serum phenylalanine $\geq 20 \mathrm{mg} / \mathrm{dL}$ ) responded to $\mathrm{BH}_{4}$. We examined 12 patients with $\mathrm{BH}_{4}$-responsive $\mathrm{PAH}$ deficiency discovered by PKU screening and evaluated the responses in the $\mathrm{BH}_{4}$ loading tests in terms of specific PAH mutations. The results have important implications for diagnosis and treatment of patients with $\mathrm{BH}_{4}$ responsive $\mathrm{PAH}$ deficiency. 


\section{PATIENTS AND METHODS}

The 12 HPA patients detected by neonatal PKU screening (Table 1) had normal amount of pteridine in urine or serum before $\mathrm{BH}_{4}$ loading, and also had normal dihydropteridine reductase activity according to the test using the Guthrie card. Blood phenylalanine concentrations at screening were in the range of $2.0-12.0 \mathrm{mg} / \mathrm{dL}$. All patients were diagnosed with mild PKU, and were given the phenylalanine-restricted diets. The criterion standard was administered between June 1995 and July 2001 at 12 medical centers in Japan.

An oral $\mathrm{BH}_{4}$ (Suntory, Tokyo, Japan) loading test was performed after demonstrating serum phenylalanine concentrations $>6 \mathrm{mg} / \mathrm{dL}$ upon instituting a normal diet, which was maintained during loading tests. In the single-dose $\mathrm{BH}_{4}$ loading test, $\mathrm{BH}_{4}(10 \mathrm{mg} / \mathrm{kg})$ was administered before breakfast; blood samples were collected at $0,4,8$, and $24 \mathrm{~h}$ after loading. In the four-dose $\mathrm{BH}_{4}$ loading test, $\mathrm{BH}_{4}$ was administered at doses of $10,10,5$, and $5 \mathrm{mg} / \mathrm{kg}$ at $0,24,36$, and $48 \mathrm{~h}$, respectively. Blood samples were obtained at $0,4,8,24$, and $52 \mathrm{~h}$ after loading. In the 1 -wk $\mathrm{BH}_{4}$ loading test, $\mathrm{BH}_{4}$ was administered for $1 \mathrm{wk}$ at $20 \mathrm{mg} / \mathrm{kg}$ in 3 p.o. daily. Blood samples were obtained before loading and after 4 and $7 \mathrm{~d}$. Long-term $\mathrm{BH}_{4}$ administration was started at $10-20 \mathrm{mg} / \mathrm{kg}$ into three doses daily; the dose was adjusted with the goal of maintaining serum phenylalanine concentrations between 2 and $4 \mathrm{mg} / \mathrm{dL}$ with a normal diet. Blood samples were obtained before administration, then weekly during the first month, and subsequently every 2 wk or month. All $\mathrm{BH}_{4}$ loading tests and long-term $\mathrm{BH}_{4}$ administration were performed after informed consent and approval of the institutional review board.

Serum phenylalanine concentrations were determined by using an automated amino acid analyzer (L-8800; Hitachi, Tokyo, Japan). Serum pteridine was measured by HPLC (LC10; Shimazu, Kyoto, Japan) after iodine oxidation. Dihydropteridine reductase activity was measured in Guthrie card specimens as described previously (3).
Genomic DNA was prepared from white blood cells using a phenol/chloroform extraction method. Each exon and its flanking intron region were amplified with a pair of human PAHspecific oligonucleotide primers (one primer being biotinylated) using a PCR. The amplified products were purified to single-stranded DNA using streptavidin-coated M280 magnetic beads (Dynal, Oslo, Norway). The purified singlestranded DNA was sequenced by the dye terminator method using an ABI PRISM 310 genetic analyzer (PerkinElmer Instruments, Norwalk, CT, U.S.A.).

\section{RESULTS}

Single-dose $\mathrm{BH}_{4}$ loading test. In eight patients (cases 1, 2, $5-8,10$, and 11) with initial serum phenylalanine concentrations of at least $9.84 \mathrm{mg} / \mathrm{dL}$, serum phenylalanine decreased gradually by $20-60 \%$ of their initial values between 4 and $24 \mathrm{~h}$ after $\mathrm{BH}_{4}$ loading (Tables 2 and 3). Among cases 3, 4, and 9, with initial values of approximately $5 \mathrm{mg} / \mathrm{dL}$, cases 3 and 9 showed the above pattern, decreasing by more than $50 \%$ of the initial phenylalanine values. Case 4 failed to show a decrease in serum phenylalanine during the loading test. Thus, the degrees of decline of serum phenylalanine in a single-dose $\mathrm{BH}_{4}$ loading test were greater than $20 \%$ in 10 of 11 patients. This test was not performed in case 12 .

Four-dose $\mathrm{BH}_{4}$ loading test. Case 4 showed a gradual decrease after $8 \mathrm{~h}$, with a $37.4 \%$ decline in serum phenylalanine in $52 \mathrm{~h}$ (Tables 2 and 3). Case 5 showed a similar response to the single-dose case. The four doses were no more effective than one in this case. The decline in serum phenylalanine induced by the four-dose $\mathrm{BH}_{4}$ loading test was $>30 \%$ in seven (cases $1-4,6,8$, and 12 ) of eight patients, ranging from $35 \%$ to $59 \%$. This test was omitted in some patients.

One-week $\mathrm{BH}_{4}$ administration test. In six patients (cases 1-5 and 8) $\mathrm{BH}_{4}$ was administered at $20 \mathrm{mg} / \mathrm{kg} / \mathrm{d}$ for $1 \mathrm{wk}$ (Tables 2 and 3). In cases 2 and 4, the 1 -wk $\mathrm{BH}_{4}$ administration was initiated immediately after the four-dose $\mathrm{BH}_{4}$ loading test

Table 1. Blood phenylalanine (Phe) in neonatal mass-screening, and preloading blood phenylalanine and serum and urine pteridines

\begin{tabular}{|c|c|c|c|c|c|c|c|c|c|}
\hline Case no. & B-Phe* (mg/dL) & Age (d) & Phe (mg/dL) & \multicolumn{2}{|c|}{ Urine (mmol/mol creat) } & $\mathrm{N} / \mathrm{B}$ & \multicolumn{3}{|c|}{ Serum $(\mathrm{nM})$} \\
\hline 2 & 10.0 & 31 & 10.5 & 6.0 & 9.2 & 0.7 & 121.7 & 75.0 & 1.6 \\
\hline 3 & 5.9 & 44 & 5.8 & 5.1 & 2.5 & 2.0 & 97.9 & 139.7 & 0.7 \\
\hline 4 & 2.0 & 50 & 4.5 & 4.1 & 5.2 & 0.8 & 50.1 & 40.8 & 1.2 \\
\hline 7 & 8.1 & 30 & 11 & $36 \%$ & $45 \%$ & 0.8 & - & - & - \\
\hline 8 & $4.0-6.0$ & 21 & 19.5 & 11.1 & 11.4 & 1.0 & 270.7 & 197.1 & 1.4 \\
\hline 9 & 4.0 & $30<$ & 6.8 & - & - & - & - & - & - \\
\hline 10 & $8.0-10.0$ & 25 & 13.2 & 3.3 & 3.7 & 0.9 & - & - & - \\
\hline 11 & 8.3 & 23 & 11.5 & 4.6 & 0.6 & 7.7 & - & - & - \\
\hline 12 & $10-12$ & $14.3 y^{\dagger}$ & $9.6 \ddagger$ & - & - & - & - & - & - \\
\hline
\end{tabular}

* Blood Phe value by mass-screening.

$\uparrow$ Data from four-dose $\mathrm{BH}_{4}$ loading test.

$\$$ Data from four-dose $\mathrm{BH}_{4}$ loading test with Phe-restricted diet $(42 \mathrm{mg} / \mathrm{kg} / \mathrm{d})$.

$\S$ Mean (SD). 
Table 2. Blood phenylalanine concentrations $(\mathrm{mg} / \mathrm{dL})$ in single-dose, four-dose, and $1-w k \mathrm{BH}_{4}$ loading tests

\begin{tabular}{|c|c|c|c|c|c|c|}
\hline Case no. & \multicolumn{2}{|c|}{ Single-dose $\mathrm{BH}_{4}$ loading } & \multicolumn{2}{|c|}{ Four-dose $\mathrm{BH}_{4}$ loading } & \multicolumn{2}{|c|}{ 1-wk $\mathrm{BH}_{4}$ loading } \\
\hline 1 & 9.8 & 6.5 & 8.6 & 3.8 & 8.5 & 4.7 \\
\hline 3 & 5.8 & 2.8 & 5.0 & 3.3 & 7.1 & 2.8 \\
\hline 4 & 4.5 & 4.5 & 5.9 & 3.7 & $3.9 \ddagger$ & 3.0 \\
\hline 5 & 10.1 & 8.0 & 7.0 & 5.9 & 12.0 & 3.0 \\
\hline 8 & 19.5 & 11.9 & 14.0 & 5.7 & $0.6 \S$ & 4.1 \\
\hline 9 & 6.8 & 2.8 & - & - & - & - \\
\hline 10 & 13.2 & 7.7 & - & - & - & - \\
\hline 11 & 11.5 & 4.4 & - & - & - & - \\
\hline 12 & - & - & 9.6 & 4.2 & - & - \\
\hline
\end{tabular}

* Continued immediately after the single-dose $\mathrm{BH}_{4}$ loading test.

$\dagger$ Continued immediately after single-dose and four-dose $\mathrm{BH}_{4}$ loading tests.

$\ddagger$ Continued immediately after the four-dose $\mathrm{BH}_{4}$ loading test.

$\S$ Continued with phenylalanine-restricted diet.

Table 3. Serum phenylalanine (Phe) decline in $\mathrm{BH}_{4}$ loading tests, $\mathrm{PKU}$ genotype, and $\mathrm{BH}_{4}$ treatment

\begin{tabular}{|c|c|c|c|c|c|c|c|c|c|c|}
\hline \multirow[b]{2}{*}{ Case no. } & \multicolumn{3}{|c|}{$\begin{array}{c}\text { Serum Phe decline }(\%) \text { in } \mathrm{BH}_{4} \\
\text { loading test }\end{array}$} & \multicolumn{2}{|c|}{$\begin{array}{l}\text { PKU genotype } \\
\text { allele }\end{array}$} & \multicolumn{5}{|c|}{ Treatment and clinical variables } \\
\hline & Single-dose & Four-dose & $1-w k$ & 1 & 2 & $\begin{array}{l}\text { Duration* } \\
\quad(\mathrm{mo})\end{array}$ & Age (mo) & Dose $\dagger(\mathrm{mg} / \mathrm{kg})$ & S-Phe (mg/ dL) & Low-Phe diet \\
\hline 1 & 34 & 56 & 45 & $\mathrm{R} 241 \mathrm{C}$ & $\mathrm{T} 278 \mathrm{I}$ & 9 & 4 & 12.2 & 3.7 & Combined $\ddagger$ \\
\hline 2 & 54 & 62 & 80 & $\mathrm{P} 407 \mathrm{~S}$ & R158W & 11 & 23 & 16.4 & 3.4 & No \\
\hline 3 & 51 & 35 & 60 & R413P & $\mathrm{A} 132 \mathrm{~V}$ & 7 & 6 & 7.9 & 3.4 & No \\
\hline 4 & 0 & 37 & 50 & $\mathrm{R} 241 \mathrm{C}$ & $\mathrm{R} 241 \mathrm{C}$ & 7 & 29 & 13.2 & 5.3 & No \\
\hline 5 & 21 & 16 & 75 & $\mathrm{R} 241 \mathrm{C}$ & P281A & 3 & 27 & 17.0 & 3.4 & No \\
\hline 6 & 59 & 46 & - & P407S & $\mathrm{R} 252 \mathrm{~W}$ & 6 & 63 & 6.6 & 9.6 & No \\
\hline 7 & 43 & - & - & R241C & R413P & 19 & 2 & 1.7 & 3.6 & Combined \\
\hline 8 & 39 & 59 & 71 & R241C & $\mathrm{R} 111 \mathrm{X}$ & - & - & - & - & Yes \\
\hline 9 & 59 & - & - & $\begin{array}{c}\text { IVS4 } \\
-1 \mathrm{~g}>\mathrm{a}\end{array}$ & A373T & 56 & 3 & 8.6 & 5.0 & No \\
\hline 10 & 42 & - & - & R413P & $\mathrm{R} 241 \mathrm{C}$ & 28 & 2 & 7.3 & 3.1 & Combined $\ddagger$ \\
\hline 11 & 62 & - & - & R241C & $\mathrm{R} 241 \mathrm{C}$ & - & - & - & - & Yes \\
\hline 12 & - & 56 & - & R413P & $\mathrm{R} 241 \mathrm{C}$ & - & - & - & - & Yes \\
\hline
\end{tabular}

* Between the first day of treatment and the last day of observation.

$\dagger$ The dose of last observation day.

$\$$ Low-Phe diet and $\mathrm{BH}_{4}$ treatment.

without waiting for an increase in serum phenylalanine. Values from the single-dose $\mathrm{BH}_{4}$ loading test in case 2 and the four-dose $\mathrm{BH}_{4}$ loading test in case 4 therefore were used as the baseline for calculating degree of decline with the 1-wk administration in these cases. In case 8 , the 1 -wk $\mathrm{BH}_{4}$ administration was carried out immediately by returning the patient to a normal diet, because low-phenylalanine diet therapy had been maintained until that time. Taking the value for the four-dose $\mathrm{BH}_{4}$ loading as a baseline, the degree of further decline was calculated. As a result, serum phenylalanine concentrations in cases 3 and 5 decreased by more than $50 \%$. The serum phenylalanine decline in case 1 was the largest observed, being $>44.7 \%$ at $15 \mathrm{mg} / \mathrm{kg}$ of $\mathrm{BH}_{4} / \mathrm{d}$ for $1 \mathrm{wk}$. Serum phenylalanine levels decreased to $3 \mathrm{mg} / \mathrm{dL}$ or less in cases 2 and 4 , with degree of reduction representing more than $50 \%$ compared with the preloading values in the single-dose or the four-dose $\mathrm{BH}_{4}$ loading test. In case 8 , the serum phenylalanine level before the 1 -wk $\mathrm{BH}_{4}$ loading test was $0.56 \mathrm{mg} / \mathrm{dL}$ within the normal range, however, during this test, serum phenylalanine kept the level as almost stable as $4 \mathrm{mg} / \mathrm{dL}$. This level did not increase under the free diet and the degree of reduction showed more than $50 \%$ compared with the preloading values in the four-dose $\mathrm{BH}_{4}$ loading test.

Long-term $\mathbf{B H}_{4}$ therapy. In case $1, \mathrm{BH}_{4}$ administration at $12.2 \mathrm{mg} / \mathrm{kg} / \mathrm{d}$ kept serum phenylalanine at $<4 \mathrm{mg} / \mathrm{dL}$ with a normal diet modified only by use of phenylalanine-free milk (Table 3). Subsequently, case 1 developed normally. Cases 2 and 3 had serum phenylalanine levels below $4 \mathrm{mg} / \mathrm{dL}$ on a normal diet under $\mathrm{BH}_{4}$ administration at 16.4 and $7.9 \mathrm{mg} / \mathrm{kg}$ per day, respectively. They had started the $\mathrm{BH}_{4}$ treatment early, and developed normally. Cases 4 and 5 had started the $\mathrm{BH}_{4}$ treatment at $2 \mathrm{y}$ of age and kept their serum phenylalanine levels below $4 \mathrm{mg} / \mathrm{dL}$ on a normal diet by $\mathrm{BH}_{4}$ mono-therapy, and showed normal mental development. In case 4 , compliance with the low phenylalanine diet resulted in a reduced caloric intake and stunted body development. After the introduction of $\mathrm{BH}_{4}$ treatment, the caloric intake recovered and the body development resumed normally.

In case 6 , the compliance with the low phenylalanine diet had been poor, resulting in serum phenylalanine above 10 
$\mathrm{mg} / \mathrm{dL} . \mathrm{BH}_{4}$ treatment was initiated at $5 \mathrm{mg} / \mathrm{kg}$ per day and then increased gradually, based on serum phenylalanine concentrations.

Cases 7 and 9 had received $\mathrm{BH}_{4}$ treatment from the beginning in the neonatal period, and both showed a good response in the single-dose $\mathrm{BH}_{4}$ loading test. Blood phenylalanine values were controlled by $\mathrm{BH}_{4}$ either given alone or combined with a restricted-phenylalanine diet. $\mathrm{BH}_{4}$ monotherapy has been pursued in case 9 for more than $4.5 \mathrm{y}$, resulting in normal physical and mental development. In case $10, \mathrm{BH}_{4}$ administration was discontinued for $1 \mathrm{y}$ due to parental constraints, leading to high serum phenylalanine concentrations. $\mathrm{BH}_{4}$ treatment was resumed after this hiatus, but unfortunately this treatment was stopped after $11 \mathrm{mo}$, again by the parental request. Cases 8 and 12 were treated with a low-phenylalanine diet without $\mathrm{BH}_{4}$ administration. The way of treatment in case 11 after $\mathrm{BH}_{4}$ loading test was unknown. Notably, no side effects were identified in the $\mathrm{BH}_{4}$-treated cases.

Among 12 patients with $\mathrm{BH}_{4}$-responsive $\mathrm{PAH}$ deficiency, 8 patients achieved their target serum phenylalanine values with $\mathrm{BH}_{4}$ alone or in combination with a phenylalanine-restricted diet, resulting in normal development. In addition, $\mathrm{BH}_{4}$ greatly improved patients' compliance and reduced the mental and physical burden upon both patients and families. The effectiveness, safety, and advantages of $\mathrm{BH}_{4}$ thus were confirmed in treatment of $\mathrm{BH}_{4}$-responsive $\mathrm{PAH}$ deficiency.

Mutations in the PAH gene. The results of gene mutation analysis are listed in Table 3. All but two patients were heterozygous, and two different mutation types were identified. The R241C mutation was detected in 8 (cases $1,4,5,7,8,10$, 11 , and 12) of 12 patients. Interestingly, two patients (cases 4 and 11) were homozygous for this mutation. The PAH R241C mutant has been reported showing $25 \%$ of the activity of wild-type PAH in a COS cell expression analysis (4).

Among the six compound heterozygotes, T278I, P281A, R111X, and R413P were detected in the other alleles. These four mutations are detected in classical PKU and result in nonfunctional PAH alleles $(5,6)$. Nevertheless, eight cases with the R241C allele showed low blood phenylalanine concentrations $(7.0 \mathrm{mg} / \mathrm{dL}$ on average) in neonatal mass-screening. In cases 2 and 6, P407S was detected in one allele and R158W and R252W in the other allele. Case 9 had A373T and IVS4 $-1 \mathrm{~g}>\mathrm{a}$ alleles. Mutant PAH molecules with P407S and A373T possess residual activity, like R241C (1). However, PAH alleles with R252W, R158W, and IVS4-1g $>$ a have no activity, thus resembling the R413P allele. Two patients with the P407S allele (cases 2 and 6) showed essentially high blood phenylalanine concentrations $(10-16 \mathrm{mg} / \mathrm{dL})$ in neonatal mass-screening.

No clear correlation was evident between the PAH mutations and the degree of decline of serum phenylalanine in the single- or four-dose $\mathrm{BH}_{4}$ loading test. In all cases, blood phenylalanine concentrations decreased gradually after $\mathrm{BH}_{4}$ administration. However, based on the results above, R241C, P407S, A132V, and A373T alleles represented the causes of mild HPA, whereas R413P, R252W, R158W, and IVS4-1g >a alleles resulted in severe HPA. Patients with mild HPA, many of whom had the $\mathrm{R} 241 \mathrm{C}$ allele, responded to $\mathrm{BH}_{4}$ administration.

\section{DISCUSSION}

Among patients with mild HPA, characterized by serum phenylalanine concentrations below $20 \mathrm{mg} / \mathrm{dL}$, a subset has shown a gradual decrease in serum phenylalanine concentrations over $1 \mathrm{~d}$ after $\mathrm{BH}_{4}$ administration (1, 2, 7-15). These patients showed no abnormalities in $\mathrm{BH}_{4}$ metabolism but had mutations in the PAH gene. Thus, a likely mechanism for $\mathrm{BH}_{4}$ responsiveness would involve the mutant $\mathrm{PAH}$ molecules with a high Michaelis-Menten constant $(\mathrm{Km})$ for $\mathrm{BH}_{4}$, requiring a higher $\mathrm{BH}_{4}$ concentration (1, 2, 7-15). Furthermore, $\mathrm{BH}_{4}$ might stabilize the mutant $\mathrm{PAH}$ molecules, considering that some of the missense mutations rendered the PAH molecule unstable, leading to a shorter half-life; this could account for the gradual nature of the effect. In either case, PAH activity should increase in response to exogenous $\mathrm{BH}_{4}$.

Accordingly, the four-dose $\mathrm{BH}_{4}$ loading test and the 1-wk trial administration were performed in patients showing decreases in blood phenylalanine in the single-dose $\mathrm{BH}_{4}$ loading test. The four-dose test was used to confirm a decline of phenylalanine in serum. The high-dose, 1-wk trial administration $(20 \mathrm{mg} / \mathrm{kg} / \mathrm{d})$ was intended to increase the diagnostic accuracy and predict the effectiveness of the long-term treatment.

We found that patients with a decrease $>20 \%$ in serum phenylalanine levels in the single-dose $\mathrm{BH}_{4}$ loading test showed a similar decrease in the four-dose test. The mean degree of lowering in the single-dose test was $40 \%$ in Japan, about half of the reduction seen in Europe; the standard dose of $\mathrm{BH}_{4}$ is $10 \mathrm{mg} / \mathrm{kg}$ in Japan, half of the $20 \mathrm{mg} / \mathrm{kg}$ dose used in Europe. These results indicated that the response to a $\mathrm{BH}_{4}$ load was dose dependent. Although case 5 showed no enhancement of effect by the four-dose $\mathrm{BH}_{4}$ administration, it showed a significant decrease in serum phenylalanine levels in the 1-wk $\mathrm{BH}_{4}$ loading test. The 1-wk trial administration confirmed $\mathrm{BH}_{4}$ effects in responsive patients, but also showed an effect in patients without any clear responsiveness in single- or fourdose $\mathrm{BH}_{4}$ loading tests. These results indicated that $\mathrm{BH}_{4}$ responsiveness becomes evident slowly, and in some cases it must be taken several days to lower blood phenylalanine. Lässker et al. (7) reported that two patients with no response to $\mathrm{BH}_{4}(7.5 \mathrm{mg} / \mathrm{kg})$ in a loading test showed a marked decrease in plasma phenylalanine after $5 \mathrm{~d}$ of $\mathrm{BH}_{4}$ administration (10 $\mathrm{mg} / \mathrm{kg})$. Moreover, although the $\mathrm{BH}_{4}$ dose $(20 \mathrm{mg} / \mathrm{kg})$ in the 1-wk trial administration was higher than the usual therapeutic dose used in $\mathrm{BH}_{4}$ deficiency in Japan, it may represent the optimal dose in $\mathrm{BH}_{4}$-responsive $\mathrm{PAH}$ deficiency, considering that $20 \mathrm{mg} / \mathrm{kg}$ is used in European countries with only minimal side effects (diarrhea and vomiting). Information from our 1-wk trial $\mathrm{BH}_{4}$ administration is helpful in dose-setting for the long-term treatment. More generally, the 1-wk $\mathrm{BH}_{4}$ administration is highly important in the differential diagnosis and treatment planning in $\mathrm{BH}_{4}$-responsive HPA.

Our genetic analyses and those reported by others indicated that $\mathrm{BH}_{4}$ responsiveness is greatly determined by mutations in 
the PAH gene, such as R241C. Spaapen et al. (8) reported four patients with $\mathrm{BH}_{4}$-responsive $\mathrm{PAH}$ deficiency; one patient with R241C/A403V mutations showed a rapid response in a combined phenylalanine and $\mathrm{BH}_{4}$ loading test, resulting in normalization of plasma phenylalanine within $8 \mathrm{~h}$. Mutant $\mathrm{PAH}$ molecules with R241C and A403V mutations were found to have respective residual activities of $25 \%$ and $32 \%$ of wildtype PAH activity. However, Trefz et al. (9) reported one mild PKU patient with E390G/IVS10-11g $>\mathrm{a}$ - a missense mutation permitting some enzyme activity and another mutation precluding activity - who showed $\mathrm{BH}_{4}$ responsiveness. They concluded that a patient with mild PKU with one mutation, resulting in limited activity, may show the $\mathrm{BH}_{4}$ reactivity even if the other mutation abolishes activity. Mutant PAH molecules with Y414C, the most common mild PKU mutation in Northern and Western Europe (4), have residual activity resembling that with R241C. Steinfeld et al. (10) reported that a patient homozygous for $\mathrm{Y} 414 \mathrm{C}$ showed a $72 \%$ decline in serum phenylalanine in a single-dose $\mathrm{BH}_{4}$ loading test $(20 \mathrm{mg} / \mathrm{kg})$. Nuoffer et al. (11) described a patient with Y414C/del194 mutations and a similar response to a $\mathrm{BH}_{4}$ load of $20 \mathrm{mg} / \mathrm{kg}$. On the other hand, Lindner and co-workers (12) found that three patients with the same genotype (Y414C/R408W) showed differing responses in a single-dose $\mathrm{BH}_{4}$ loading test $(20 \mathrm{mg} / \mathrm{kg})$. Blood phenylalanine levels decreased to the normal range in one patient, but not in the other two patients, despite normal $\mathrm{BH}_{4}$ absorption; the authors concluded that $\mathrm{BH}_{4}$ responsiveness in PAH deficiency is at least partly independent of PAH genotype. Although the first mutation, Y414C, has some residual activity (4), R408W is a known null mutation that completely abolishes enzyme activity on the affected allele and is associated with only minimal amounts of PAHimmunoreactive protein according to in vitro expression studies (16). Therefore, the mutant PAH molecule with Y414C/ $\mathrm{R} 408 \mathrm{~W}$ catalyzed the phenylalanine-hydroxylation reaction at a lower rate than that seen in a $\mathrm{Y} 414 \mathrm{C}$ homozygote, rendering $\mathrm{BH}_{4}$ responsiveness in patients with $\mathrm{Y} 414 \mathrm{C} / \mathrm{R} 408 \mathrm{~W}$ more variable than in Y414C homozygote. Although no clear correlation was seen between the degrees of lowering of the serum phenylalanine in the $\mathrm{BH}_{4}$ loading test and $\mathrm{PAH}$ mutations, at least one mild PKU mutation or missense mutation was found in patients with $\mathrm{BH}_{4}$ responsiveness. Erlandsen and Stevens (13) indicated that these mutations can be located in the cofactor-binding regions or in those that closely interact with the cofactor-binding regions. However Blau and Trefz (14) reported that a patient with $\mathrm{BH}_{4}$ responsiveness had the homozygous L48S mutation in the PAH gene that has located in the regulatory domain (exon 1-5). Muntau et al. (15) classified seven mutations (P314S, Y417H, V177M, V245A, A300S, E390G, and IVS4-5C->G) as probably associated with responsiveness to $\mathrm{BH}_{4}$, six mutations (A403V, F39L, D415N, $\mathrm{S} 310 \mathrm{Y}, \mathrm{R} 158 \mathrm{Q}$, and I65T) as potentially associated, and four mutations (Y414C, L48S, R261Q, and I65V) as inconsistently associated with this phenotype, and stated that mutations connected to $\mathrm{BH}_{4}$ responsiveness were predominantly in the catalytic domain of the protein and were not directly involved in cofactor binding. Therefore, the mechanism underlying $\mathrm{BH}_{4}$ responsiveness in PAH deficiency is still incompletely understood.
Discovery of $\mathrm{BH}_{4}$-responsive $\mathrm{PAH}$ deficiency has significant clinical implications. Sufficient amounts of $\mathrm{BH}_{4}$ easily could be given to treat this disorder, inasmuch as serum phenylalanine concentrations were controlled to within 4 $\mathrm{mg} / \mathrm{dL}$ by $\mathrm{BH}_{4}$ monotherapy or by $\mathrm{BH}_{4}$ combined with relatively mild dietary phenylalanine restriction. A rigorous restricted-phenylalanine diet involves a great deal of long-term effort for patients and their families. $\mathrm{BH}_{4}$ treatment of responsive patients can eliminate or reduce the need for phenylalanine-restriction. Accurate diagnosis of $\mathrm{BH}_{4}$ responsiveness therefore is very important. In this study, $\mathrm{BH}_{4}$ responsiveness appeared to be regulated by mild PKU mutations in PAH gene, and was affected by the dose and administration period of $\mathrm{BH}_{4}$. Based on our genetic analysis, the rate of R241C or P407S mutations among $\mathrm{BH}_{4}$-responsive $\mathrm{PAH}$ deficiency is $83 \%$ in Japan. Thus, gene analysis should be performed on all HPA patients. One-week $\mathrm{BH}_{4}$ administration at $20 \mathrm{mg} / \mathrm{kg} / \mathrm{d}$ was the most sensitive test for diagnosis of $\mathrm{BH}_{4}$-responsive $\mathrm{PAH}$ deficiency, and this additional test should be performed in all PKU patients who show more than a $20 \%$ decrease of blood phenylalanine in a single-dose $\mathrm{BH}_{4}$ loading test, or who have $\mathrm{R} 241 \mathrm{C}$ or P407S mutations.

Treatment with $\mathrm{BH}_{4}(5-20 \mathrm{mg} / \mathrm{kg} / \mathrm{d})$ is a new and effective pharmacotherapy that can replace a restricted-phenylalanine diet in some mild PKU patients. $\mathrm{BH}_{4}$ has already been marketed as an approved drug for $\mathrm{BH}_{4}$ deficiency. The rate of $\mathrm{BH}_{4}$-responsive PAH deficiency among PKU is about $10 \%$ in Japan, and is apparently higher than that of $\mathrm{BH}_{4}$ deficiency. Nevertheless, $\mathrm{BH}_{4}$ is not yet approved for $\mathrm{BH}_{4}$-responsive $\mathrm{PAH}$ deficiency, and effects of high doses of $\mathrm{BH}_{4}$ have not been examined in large numbers of patients. Caution and careful observation of clinical changes will be necessary to successfully bring $\mathrm{BH}_{4}$ treatment to the clinic for this indication.

Acknowledgment. The authors thank Tomoko Kajita for expert technical assistance. We also thank Dr. Toshiaki Oura, Dr. Keiya Tada, and Dr. Ichiro Matsuda for critically reviewing the manuscript.

\section{REFERENCES}

1. Kure S, Hou DC, Ohura T, Iwamoto H, Suzuki S, Sugiyama N, Sakamoto O, Fujii K, Matsubara Y, Narisawa K 1999 Tetrahydrobiopterin-responsive phenylalanine hydroxylase deficiency. J Pediatr 135:375-378

2. Shintaku H, Asada M, Sawada Y, Yamano T 2000 Tetrahydrobiopterin-responsive hyperphenylalaninemia without biopterin deficiency. Pteridines 11:83-84

3. Arai N, Narisawa K, Hayakawa H, Tada K 1982 Hyperphenylalaninemia due to dihydropteridine reductase deficiency: diagnosis by enzyme assays on dried blood spots. Pediatrics 70:426-430

4. Okano Y, Eisensmith RC, Dasovich M, Wang T, Guttler F, Woo SL 1991 A prevalent missense mutation in Northern Europe associated with hyperphenylalaninaemia. Eur J Pediatr 150:347-352

5. Okano Y, Asada M, Kang Y, Nishi Y, Hase Y, Oura T, Isshiki G 1998 Molecular characterization of phenylketonuria in Japanese patients. Hum Genet 103:613618

6. Takahashi K, Kure S, Matsubara Y, Narisawa K 1992 Novel phenylketonuria mutation detected by analysis of ectopically transcribed phenylalanine hydroxylase mRNA from lymphoblast. Lancet 340:1473

7. Lässker U, Zschocke J, Blau N, Santer R 2002 Tetrahydrobiopterin responsiveness in phenylketonuria. Two new cases and a review of molecular genetic findings. J Inherit Metab Dis 25:65-70

8. Spaapen LJ, Bakker JA, Velter C, Loots W, Rubio-Gozalbo ME, Forget PP, Dorland L, De Koning TJ, Poll-The BT, Ploos van Amstel HK, Bekhof J, Blau N, Duran M, Rubio-Gonzalbo ME 2001 Tetrahydrobiopterin-responsive phenylalanine hydroxylase deficiency in Dutch neonates. J Inherit Metab Dis 24:352-358 
9. Trefz FK, Aulela-Scholz C, Blau N 2001 Successful treatment of phenylketonuria with tetrahydrobiopterin. Eur J Pediatr 160:315

10. Steinfeld R, Kohlschutter A, Zschocke J, Lindner M, Ullrich K, Lukacs Z 2001 Tetrahydrobiopterin-responsiveness associated with common phenylalaninehydroxylase mutations distant from the tetrahydrobiopterin binding site. J Inherit Metab Dis 24:29

11. Nuoffer JM, Töny B, Romstad A, Blau N 2001 A patient with phenylketonuria successfully treated with tetrahydrobiopterin. J Inherit Metab Dis 24:29

12. Lindner M, Haas D, Mayatepek E, Zschocke J, Burgard P 2001 Tetrahydrobiopterin responsiveness in phenylketonuria differs between patients with the same genotype. Mol Genet Metab 73:104-106
13. Erlandsen H, Stevens RC 2001 A structural hypothesis for $\mathrm{BH}_{4}$ responsiveness in patients with mild forms of hyperphenylalaninaemia and phenylketonuria. J Inherit Metab Dis 24:213-230

14. Blau N, Trefz FK 2002 Tetrahydrobiopterin-responsive phenylalanine hydroxylase deficiency: possible regulation of gene expression in a patient with the homozygous L48S mutation. Mol Genet Metab 75:186-187

15. Muntau AC, Roschinger W, Habich M, Demmelmair H, Hoffmann B, Sommerhoff CP, Roscher AA 2002 Tetrahydrobiopterin as an alternative treatment for mild phenylketonuria. N Engl J Med 347:2122-2132

16. DiLella AG, Marvit J, Brayton K, Woo SL 1987 An amino-acid substitution involved in phenylketonuria is in linkage disequilibrium with DNA haplotype 2. Nature 327:333-336 